\title{
Selection of Genetically Divergent Clones of Casuarina equisetifolia for Further Breeding Programmes
}

\author{
By Kannan C. S. Warrier*) and B. Gurudevsingh \\ Division of Genetics and Tree Breeding, Institute of Forest Genetics and Tree Breeding \\ (Indian Council of Forestry Research and Education) \\ PB 1061, R.S. Puram Post - 641 002, Coimbatore, Tamil Nadu
}

(Received $10^{\text {th }}$ December 2009)

\begin{abstract}
Summary
Genetic divergence studies were carried out in clones of Casuarina equisetifolia L. selected from Chidambaram/Chengalpet (CH/CP) and Tiruchendur (TCR) in Tamil Nadu, India. $33 \mathrm{CH} / \mathrm{CP}$ clones and 43 TCR clones were subjected to the analysis separately at 8 years of age. Mahalanobis' $\mathrm{D}^{2}$ technique was used to study the genetic divergence and the clones were grouped into different clusters using the Tocher's method. Tree height, diameter at breast height, collar diameter, crown length, cladode length, cladode diameter, number of primary branches, frustum volume and volume index were the characters used for the analysis. Application of Mahalanobis' $\mathrm{D}^{2}$ statistics and Tocher's clustering method grouped the $\mathrm{CH} / \mathrm{CP}$ clones into eleven clusters with cluster strength varying from one (clusters $\mathrm{X}$ and $\mathrm{XI}$ ) to eleven (cluster V) and the TCR clones into seven clusters with cluster strength from one in cluster VII to twelve in cluster VI. Among the various characters, volume index contributed the maximum towards genetic divergence. Based on the inter and intra-cluster distances, male clones $\mathrm{CH}$ 3004, CH 0401, CP 0207, CP 3903, CH 2604 and CP 1501 and female clones CH 2703, CH 2803, CP 3703, CP 0301 and CH 3002 are recommended for further breeding programmes from the $\mathrm{CH} / \mathrm{CP}$ group. From the TCR group of clones, TCR 110202, TCR 090201 and TCR 030101 (male) and female clones, TCR 040204, TCR 120102, TCR 080201, TCR 120203 and TCR 090102 are recommended. The results on genetic divergence have got an immediate application in the establishment of clonal seed orchards. Information on genetic distance between genotypes helps in developing planting design, such that it can facilitate equal opportunity for hybridization among the genotypes and obtaining quality seeds with high vigour.
\end{abstract}

Key words: Genetic Divergence, Casuarina equisetifolia, Tree Breeding, Hybridization.

\section{Introduction}

India is the largest Casuarina growing country in the world with an estimated 800,000 ha of plantations (PinYopusarerk and Williams, 2000). Nicodemus (2009) estimated that about 500,000 ha are planted with Casuarina in the states of Andhra Pradesh, Orissa, Tamil Nadu and the Union Territory of Puducherry. Casuarina equisetifolia L. is the most widely planted

\footnotetext{
*) Corresponding Author: KanNAN C. S. WARRIER.

Phone: 91422 2484100, Fax: 914222430549.

E-Mail: kannan@icfre.org, kannanwarrier@gmail.com
}

species of Casuarina in India. Its amenability to short rotation and a sustained market demand as scaffolding in building industry, cheap housing material, banana stakes and excellent fuelwood are keys for its success (KONDAS, 1983). Its nitrogen fixing ability, desirable stem form, fast growth and light crown characteristics make it an ideal tree for agroforestry systems (VISWANATH et al., 2001).

In Casuarina equisetifolia abundant phenotypic variations are reported throughout its distribution range in India. Striking phenotypic variations were observed in shape of crown, branch angle, length of branchlets, size and shape of cones and seeds in the east coast of Tamil Nadu (KondAs, 1983). This species is reported to show tremendous variation in growth parameters also, (Kumar and Gurumurthi, 1998; Prasad and Dieters, 1998) thus offering opportunities for further improvement through hybridization. Identification of genetically divergent genotypes is a pre requisite for any hybridization programme or to select the materials for seed orchard purposes. Therefore, a study was conducted to understand the genetic divergence in this species at the Institute of Forest Genetics and Tree Breeding (IFGTB), Coimbatore.

\section{Materials and Methods \\ Background of Trial Clones}

The experimental materials comprised of clones of C. equisetifolia selected from Chidambaram/Chengalpet $(\mathrm{CH} / \mathrm{CP})$ and Tiruchendur (TCR) in Tamil Nadu, India. Extensive survey of 4 year old $C$. equisetifolia seed raised plantations established by the Tamil Nadu Forest Department was carried out in the above said regions and selection of trees was carried out by dividing each of the plantations into grids (blocks) to minimize the soil heterogeneity effect on the performance of individual trees. In each grid, trees with good tree height, high collar diameter (CDM) and diameter at breast height $(\mathrm{DBH})$, straight and clear main bole, narrow crown with fewer branches and no incidence of disease and pests were selected. The block adjustments of phenotypical values were carried out following COTTERILL and DEAN (1990). The phenotypic selection was followed by the construction of selection index for each selected tree with the block adjusted phenotypical values. The main bole volume was considered as the principal trait for the construction of selection index and its correlation with 
tree height, CDM, DBH, frustum volume and pole value was estimated. The index of each character was calculated by multiplying the block adjusted phenotypic value with the correlation coefficient of the trait with main bole volume, since the correlation coefficient of main bole volume with other traits was considered as the weightage for the index selection. The total selection index was calculated by adding all the six values for each selected tree.

$$
\mathrm{TSI}=\mathrm{x}_{1} \mathrm{R}_{1,6}+\mathrm{x}_{2} \mathrm{R}_{2,6}+\mathrm{x}_{3} \mathrm{R}_{3,6}+\mathrm{x}_{4} \mathrm{R}_{4,6}+\mathrm{x}_{5} \mathrm{R}_{5,6}+\mathrm{x}_{6}
$$

where, TSI is the total selection index, $x_{1}, x_{2}, x_{3}, x_{4}, x_{5}$ and $\mathrm{x}_{6}$ are the block adjusted phenotypic values for tree height, CDM, DBH, frustum volume, pole value and main bole volume, respectively and $R_{1,6}, R_{2,6}, R_{3,6}, R_{4,6}$, $R_{5,6}$ are the correlation coefficients (weightage) for tree height, CDM, DBH, frustum volume and pole value with the main bole volume, respectively. After calculating selection index for all the initially marked trees, final selection of superior trees was carried out. Sprigs collected from the lower branches of the selected trees were rooted to produce clonal materials and they were planted in the clone bank of IFGTB at Coimbatore. (KUMAR and Gurumurthi, 1998; Balasubramanian, 2000). There was no genetic resource exchange between the two experimental locations.

\section{Experimental Design}

The experiment was laid out in a Randomized Complete Block Design with 6 replications (3 ramets per replication). Thirty-three $\mathrm{CH} / \mathrm{CP}$ clones and 43 TCR clones were analyzed separately (as they were introduced at different periods) during the study.

\section{Trait Observation Data Collection and Calculation}

All the ramets were treated equally during their 8 years of growth and the survival rate was 100 per cent. At 8 years of age, the 9 traits were measured or calculated as followings:

Tree height $(\mathbf{H})$ was measured using Ravi Multimeter (Ravi Vaigyanik Yantra Nirmata, Dehra Dun, India) in metre. DBH was measured at $1.37 \mathrm{~m}$ from the ground level using an electronic digital vernier calliper (Mitutoyo Corporation, Japan) in centimetre. CDM was measured at the collar region using electronic digital vernier calliper in centimetre. Crown length (CRL) was vertical measurement of the crown of the tree from the tip to the point half way between the lowest green branches forming green crown all round and the lowest green branch on the bole in metre (CHATURVEDI and Khanna, 1982). Cladode length (CLL) was average length of 50 randomly selected cladodes (all along the tree) per ramet measured using a scale in centimetre. Cladode diameter (CLD) was average diameter (at the base) of 50 randomly selected cladodes per ramet measured using digital vernier calliper in millimetre. Number of primary branches (NPB) was counted the total number of branches formed from the main bole of the tree. Frustum volume (FV) was calculated by Smalian's formula given by CheTurvedi and KHANnA (1982).
Frustum volume $=\frac{\mathrm{s}_{1}+\mathrm{s}_{2}}{2} \times 1\left(\mathrm{~cm}^{3}\right)$

Where, $\mathrm{s}_{1}=(\mathrm{CDM} / 2)^{2} \times \pi\left(\mathrm{cm}^{2}\right), \mathrm{s}_{2}=(\mathrm{DBH} / 2)^{2} \times \pi$ $\left(\mathrm{cm}^{2}\right), \mathrm{l}=137 \mathrm{~cm}$

Volume index $\left(\mathbf{D}^{2} \mathbf{H}\right)$ was the product of square of $\mathrm{DBH}$ and tree height as a surrogate for total tree volume (ELLioTt et al., 2002) and expressed in $\mathrm{cm}^{3}$.

All the clones were evaluated using point grading method at age 8. It is an integrated method of evaluation where both quantitative and qualitative characters are considered for grading the individuals (JAYARAJ et al., 1997; WARRIER et al., 2004). Point grading method is applicable only to even-aged clonal accessions and not for evaluation across sites. Tree height and $\mathrm{DBH}$ were the quantitative characters studied. Qualitative characters assessed included stem form, branching habits and health status. Axis persistence, straightness, verticality and bole swelling were the characters used for assessing stem form. Branch thickness, branch angle and branch length were considered for understanding the branching habits. Blister bark disease caused by Trichosporium vesiculosum, root rot disease by Ganoderma lucidum and stem borer attack by Indarbela quadrinotata are the major health hazards for this species. For quantitative traits, each clone was awarded points based on the extent to which the mean value for the trait was close to the maximum mean value recorded for any clone. All the other qualitative traits were subjectively scored for each clone and not judged in relation to the other clones. While assessing the same, characters expressed by more than 90 per cent of the ramets were considered specific to that clone.

\section{Data Treatment}

Mahalanobis' $\mathrm{D}^{2}$ technique (MAHALANOBIS, 1928) was used to study the genetic divergence. The estimation of $\mathrm{D}^{2}$ values is very complicated especially when the number of characters being studied becomes large because it needs inversion of matrix of higher order. The computation is very much simplified when the characters under study are independent and are expressed in terms of their respective standard errors. Therefore, the correlated variables were transformed into uncorrelated ones by using pivotal condensation method. The significance of the $\mathrm{D}^{2}$ values was tested against the tabulated value of chi-square for ' $p$ ' degrees of freedom where, 'p' is the number of characters considered.

Clones were grouped into different clusters using the Tocher's method (RAO, 1952). The first step for grouping was to arrange the clones in order of their relative distances from each other based on $\mathrm{D}^{2}$ values. Two clones having smallest distance from each other were considered first to which a third clone having smallest average $\mathrm{D}^{2}$ value from the first two clones was added. The nearest fourth clone was chosen next and the process was continued up to a stage where there was abrupt increase in the average $\mathrm{D}^{2}$ after adding a particular clone. Similarly, other clusters were formed omitting the clones, which had already been included. The process was continued till all the clones were included into one or other cluster. 
After forming the clusters, the intra and inter cluster relationships were studied. The average intra cluster distances were measured using the formula $\sum \mathrm{D}_{\mathrm{i}}^{2} / \mathrm{n}$ where, $\sum \mathrm{D}_{\mathrm{i}}{ }^{2}$ is the sum of distances between all possible combinations $(\mathrm{n})$ of the clones included in a cluster. The average inter cluster distances were worked out by taking into consideration all the component $\mathrm{D}^{2}$ values possible among the members of the two clusters considered. The square root of the average $\mathrm{D}^{2}$ values gave the genetic distance ' $D$ ' between or within clusters. The analysis was performed using the software SPAR (Statistical Package for Agricultural Research developed by the Indian Agricultural Statistics Research Institute, New Delhi, India).

\section{Results and Discussion}

A logical way to start any breeding programme is to survey the variations present in the germplasm
(Chaturvedi and Pandey, 2001). A clear understanding of the degree of divergence for important traits will be an added advantage in this regard, as inter-mating of divergent groups would increase variability and range of frequency distribution (ALICCHIO and PALENZONA, 1974). When large number of phenotypically superior genotypes of a species are available due to initial selections, the $\mathrm{D}^{2}$ statistics and clustering technique help to form genetically homogeneous groups and representative samples from such groups will reduce the number of entries of genetically similar selections/provenances for inclusion in the establishment of provenance trials, progeny trials and seed orchards (BAGCHI, 2000). Reduced entries will reduce the total area required for planting and in turn reduce the cost of the tree improvement programme.

Application of Mahalanobis' $\mathrm{D}^{2}$ statistics and Tocher's clustering method grouped the $33 \mathrm{CH} / \mathrm{CP}$ clones into 11 clusters with cluster strength varying from one (clusters

Table 1. - Clustering among $\mathrm{CH} / \mathrm{CP}$ clones based on Mahalanobis' $\mathrm{D}^{2}$ analysis.

\begin{tabular}{|c|c|c|}
\hline Cluster & Number of Clones & Clone Identification Number \\
\hline I & 6 & $\begin{array}{l}\text { CH 3004, CP 4305, CP } 3703, \\
\text { CP 3702, CP 3901, CP } 1501\end{array}$ \\
\hline II & 2 & CP 0203, CP 4805 \\
\hline III & 2 & CP 4202, CH 1004 \\
\hline IV & 2 & CH 2602, CH 2002 \\
\hline $\mathrm{V}$ & 11 & $\begin{array}{l}\text { CP } 1802, \text { CP 4403, CP 0301, } \\
\text { CP 0110, CP 0207, CP 0108, } \\
\text { CH 2703, CH 1802, CH 3002, } \\
\text { CH 2604, CH } 1002\end{array}$ \\
\hline VI & 2 & CH 0903, СH 0803 \\
\hline VII & 2 & CP 3101, CP 2401 \\
\hline VIII & 2 & CH 2803, CP 3903 \\
\hline IX & 2 & CP 3501, CH 2303 \\
\hline $\mathrm{X}$ & 1 & $\mathrm{CH} 0401$ \\
\hline XI & 1 & CH 1702 \\
\hline
\end{tabular}

Table 2. - Average inter and intra cluster $\mathrm{D}$-square values for $\mathrm{CH} / \mathrm{CP}$ clones.

\begin{tabular}{|c|c|c|c|c|c|c|c|c|c|c|c|}
\hline Cluster & I & II & III & IV & $\mathrm{V}$ & $\mathrm{VI}$ & VII & VIII & IX & $X$ & $\mathrm{XI}$ \\
\hline I & 30.63 & 25.95 & 28.98 & 30.56 & 34.12 & 38.68 & 35.67 & 32.46 & 26.26 & 57.20 & 48.63 \\
\hline II & & 3.197 & 13.27 & 13.33 & 21.57 & 18.64 & 29.64 & 20.21 & 25.37 & 24.49 & 26.87 \\
\hline III & & & 3.92 & 26.24 & 25.98 & 31.85 & 25.86 & 28.32 & 16.91 & 42.05 & 32.26 \\
\hline IV & & & & 4.65 & 30.93 & 27.89 & 23.27 & 38.25 & 40.05 & 31.08 & 18.10 \\
\hline V & & & & & 34.42 & 32.07 & 30.11 & 37.69 & 27.12 & 52.68 & 36.92 \\
\hline VI & & & & & & 9.93 & 34.23 & 53.20 & 35.73 & 51.92 & 20.94 \\
\hline VII & & & & & & & 13.14 & 54.93 & 23.70 & 65.29 & 16.95 \\
\hline VIII & & & & & & & & 15.14 & 35.24 & 35.44 & 68.32 \\
\hline IX & & & & & & & & & 17.15 & 73.54 & 43.27 \\
\hline$X$ & & & & & & & & & & 0 & 54.46 \\
\hline XI & & & & & & & & & & & 0 \\
\hline
\end{tabular}


Table 3. - Average inter and intra cluster distances for $\mathrm{CH} / \mathrm{CP}$ clones.

\begin{tabular}{|c|c|c|c|c|c|c|c|c|c|c|c|}
\hline Cluster & $\mathrm{I}$ & II & III & IV & $\mathrm{V}$ & VI & VII & VIII & IX & $\mathrm{X}$ & XI \\
\hline I & 5.54 & 5.09 & 5.38 & 5.53 & 5.84 & 6.22 & 5.97 & 5.70 & 5.12 & 7.56 & 6.97 \\
\hline II & & 1.79 & 3.64 & 3.65 & 4.64 & 4.32 & 5.44 & 4.50 & 5.04 & 4.95 & 5.18 \\
\hline III & & & 1.98 & 5.12 & 5.10 & 5.64 & 5.09 & 5.32 & 4.11 & 6.49 & 5.68 \\
\hline IV & & & & 2.16 & 5.56 & 5.28 & 4.82 & 6.19 & 6.33 & 5.58 & 4.25 \\
\hline V & & & & & 5.87 & 5.66 & 5.49 & 6.14 & 5.21 & 7.26 & 6.08 \\
\hline VI & & & & & & 3.15 & 5.85 & 7.29 & 5.98 & 7.21 & 4.58 \\
\hline VII & & & & & & & 3.63 & 7.41 & 4.87 & 8.08 & 4.12 \\
\hline VIII & & & & & & & & 3.89 & 5.94 & 5.95 & 8.27 \\
\hline IX & & & & & & & & & 4.14 & 8.58 & 6.58 \\
\hline X & & & & & & & & & & 0 & 7.38 \\
\hline XI & & & & & & & & & & & 0 \\
\hline
\end{tabular}

$\mathrm{X}$ and $\mathrm{XI}$ ) to eleven (cluster V). Cluster X which contained one clone, $\mathrm{CH} 0401$ (male) registered the maximum mean values for all the important traits including H, DBH, CDM, CRL, NPB, FV and VI. (Tables 1 to 5) followed by cluster VIII consisting of two clones, $\mathrm{CH}$ 2803 (female) and CP 3903 (male). Cluster I with six clones also recorded higher mean values for all the traits. The male clone which ranked the top for VI was included in this cluster. Among the various characters, VI contributed the maximum $(26.14 \%)$ towards genetic divergence. All these three clusters (I, VIII and X) were found to be highly divergent from most of the other clus- ters. The fastest growing female clone, $\mathrm{CH} 2703$ (data not shown) was included in cluster $\mathrm{V}$ and the inter-cluster distances between this cluster and clusters X and I were very high.

With reference to the qualitative traits, all the clones included in these four clusters received the maximum favourable score for straightness (5), axis persistence (8) and verticality (4). Thickness of branches was observed to be very light (5). Most of the individuals possessed short branches (less than $1 / 4$ th of the tree height (score 3 )) with branch angle varying between 45 to $60^{\circ}$ (3). All these clones were free from disease and pest problems

Table 4. - Cluster means for various characters of $\mathrm{CH} / \mathrm{CP}$ clones.

\begin{tabular}{cccccccccc}
\hline Cluster & \multicolumn{70}{c}{ Characters } \\
\hline & $\begin{array}{c}\text { Tree } \\
\text { Height }\end{array}$ & DBH & $\begin{array}{c}\text { Collar } \\
\text { Diameter }\end{array}$ & $\begin{array}{c}\text { Crown } \\
\text { Length }\end{array}$ & $\begin{array}{c}\text { Cladode } \\
\text { Length }\end{array}$ & $\begin{array}{c}\text { Cladode } \\
\text { Diameter }\end{array}$ & $\begin{array}{c}\text { Primary } \\
\text { Branches }\end{array}$ & $\begin{array}{c}\text { Frustum } \\
\text { Volume }\end{array}$ & $\begin{array}{c}\text { Volume } \\
\text { Index }\end{array}$ \\
\hline & & & & & & & & & \\
I & 12.60 & 6.33 & 7.74 & 5.98 & 13.88 & 0.50 & 26.11 & 6628.66 & 73304.91 \\
II & 12.60 & 6.33 & 7.69 & 5.45 & 13.08 & 0.33 & 33.50 & 5478.50 & 53541.52 \\
III & 11.85 & 5.98 & 8.10 & 5.30 & 15.88 & 0.34 & 30.75 & 5562.68 & 43791.42 \\
IV & 11.30 & 4.94 & 6.04 & 3.68 & 11.48 & 0.33 & 19.50 & 3398.45 & 29417.57 \\
V & 11.39 & 5.86 & 7.23 & 5.05 & 13.88 & 0.43 & 30.35 & 5271.87 & 52618.43 \\
VI & 11.11 & 5.60 & 7.28 & 5.14 & 9.37 & 0.41 & 35.00 & 4777.69 & 37986.52 \\
VII & 8.38 & 3.96 & 5.19 & 2.65 & 14.06 & 0.44 & 19.17 & 2356.90 & 13931.82 \\
VIII & 15.20 & 7.20 & 8.59 & 6.66 & 16.22 & 0.45 & 35.25 & 6875.71 & 81615.797 \\
IX & 10.47 & 5.19 & 6.57 & 5.39 & 16.23 & 0.49 & 29.33 & 3869.14 & 29639.81 \\
X & 16.87 & 10.24 & 12.68 & 7.11 & 11.55 & 0.30 & 36.00 & 14325.91 & 177164.86 \\
XI & 8.69 & 3.77 & 5.20 & 3.45 & 10.50 & 0.30 & 22.67 & 2323.15 & 13597.48 \\
\hline
\end{tabular}

Table 5. - Relative contribution of characters towards divergence in $\mathrm{CH} / \mathrm{CP}$ clones.

\begin{tabular}{lcc}
\hline \multicolumn{1}{c}{ Characters } & No. of Times Ranked First & Percentage Contribution \\
\hline & & \\
Tree Height & 84 & 15.91 \\
Diameter at Breast Height & 26 & 4.92 \\
Collar Diameter & 07 & 1.33 \\
Crown Length & 20 & 3.79 \\
Cladode Length & 78 & 14.77 \\
Cladode Diameter & 73 & 13.83 \\
No. of Primary Branches & 51 & 9.66 \\
Frustum Volume & 51 & 9.66 \\
Volume Index & 138 & 26.14 \\
\hline
\end{tabular}


Table 6. - Clustering among TCR clones based on Mahalanobis' $\mathrm{D}^{2}$ analysis.

\begin{tabular}{|c|c|c|}
\hline Cluster & Number of Clones & Clone Identification Number \\
\hline I & 2 & TCR 030201,TCR 090202 \\
\hline II & 9 & $\begin{array}{l}\text { TCR 070201, TCR 050203, TCR } 050202 \\
\text { TCR 060202, TCR 020101, TCR } 070102 \\
\text { TCR 080103, TCR 060101, TCR } 010103\end{array}$ \\
\hline III & 4 & $\begin{array}{l}\text { TCR 120102, TCR } 080203 \text {, TCR } 030202, \\
\text { TCR } 030101\end{array}$ \\
\hline IV & 5 & $\begin{array}{c}\text { TCR 110202, TCR 080201, TCR 120203, } \\
\text { TCR } 100101, \text { TCR } 110203\end{array}$ \\
\hline $\mathrm{V}$ & 10 & $\begin{array}{l}\text { TCR 090102, TCR 020105, TCR } 100104, \\
\text { TCR 090201, TCR 100203, TCR 010101, } \\
\text { TCR 110101, TCR 030203, TCR 040104 } \\
\text { TCR } 020102\end{array}$ \\
\hline VI & 12 & $\begin{array}{l}\text { TCR } 090101 \text {, TCR } 020202, \text { TCR } 100102 \text {, } \\
\text { TCR } 030106 \text {, TCR } 120202 \text {, TCR } 130202 \text {, } \\
\text { TCR } 120204 \text {, TCR } 01012 \text {, TCR } 110102 \text {, } \\
\text { TCR } 040103 \text {, TCR } 080102 \text {, TCR } 060204\end{array}$ \\
\hline VII & 1 & TCR 040204 \\
\hline
\end{tabular}

Table 7. - Average inter and intra cluster D-square values for TCR clones.

\begin{tabular}{clllllrr}
\hline Cluster & I & II & III & IV & V & VI & VII \\
\hline & & & & & & & \\
I & \multirow{2}{*}{1.34} & 26.56 & 30.76 & 35.54 & 19.44 & 27.08 & 10.54 \\
II & & 13.45 & 24.92 & 26.35 & 25.32 & 27.88 & 41.55 \\
III & & & 20.06 & 20.21 & 25.94 & 26.63 & 30.24 \\
IV & & & & 24.76 & 31.29 & 30.54 & 35.65 \\
V & & & & 21.42 & 23.49 & 32.05 \\
VI & & & & & & 22.60 & 40.66 \\
VII & & & & & & & 0.00 \\
\hline
\end{tabular}

Table 8. - Average inter and intra cluster distances for TCR clones.

\begin{tabular}{clllllll}
\hline Cluster & I & II & III & IV & V & VI & VII \\
\hline & & & & & & & \\
I & \multirow{2}{*}{1.16} & 5.15 & 5.55 & 5.96 & 4.41 & 5.20 & 3.25 \\
II & & 3.67 & 4.99 & 5.13 & 5.03 & 5.28 & 6.45 \\
III & & & 4.48 & 4.50 & 5.09 & 5.16 & 5.50 \\
IV & & & & 4.98 & 5.59 & 5.53 & 5.97 \\
V & & & & 4.63 & 4.85 & 5.66 \\
VI & & & & & & 4.75 & 6.38 \\
VII & & & & & & \\
\hline
\end{tabular}

Table 9. - Cluster means for various characters of TCR clones.

\begin{tabular}{cccccccccc}
\hline Cluster & \multicolumn{10}{c}{ Characters } \\
\hline & $\begin{array}{c}\text { Tree } \\
\text { Height }\end{array}$ & DBH & $\begin{array}{c}\text { Collar } \\
\text { Diameter }\end{array}$ & $\begin{array}{c}\text { Crown } \\
\text { Length }\end{array}$ & $\begin{array}{c}\text { Cladode } \\
\text { Length }\end{array}$ & $\begin{array}{c}\text { Cladode } \\
\text { Diameter }\end{array}$ & $\begin{array}{c}\text { Primary } \\
\text { Branches }\end{array}$ & $\begin{array}{c}\text { Frustum } \\
\text { Volume }\end{array}$ & $\begin{array}{c}\text { Volume } \\
\text { Index }\end{array}$ \\
\hline & & & & & & & & & \\
I & 9.92 & 6.12 & 7.99 & 2.90 & 23.01 & 0.47 & 32.08 & 5745.72 & 41919.54 \\
II & 9.29 & 4.91 & 6.34 & 3.19 & 16.73 & 0.49 & 28.00 & 3584.82 & 24520.24 \\
III & 11.78 & 7.62 & 9.58 & 3.80 & 16.18 & 0.57 & 34.29 & 8439.82 & 75334.53 \\
IV & 11.55 & 7.11 & 9.03 & 3.50 & 15.76 & 0.54 & 35.07 & 8207.67 & 76092.07 \\
V & 8.95 & 5.82 & 7.42 & 2.55 & 18.33 & 0.53 & 31.28 & 4925.24 & 32221.32 \\
VI & 8.72 & 5.61 & 7.70 & 2.70 & 17.13 & 0.55 & 36.31 & 5273.22 & 33237.13 \\
VII & 12.76 & 8.64 & 10.63 & 3.74 & 23.38 & 0.48 & 34.67 & 10263.41 & 99718.45 \\
\hline
\end{tabular}


when examined for blister bark disease, root rot disease and stem borer attack. The rooting ability was noticed to be satisfactory (above 70 per cent).

According to SingH and ChaudhaRY (1985), three important points which need to be essentially considered while selecting genotypes include (a) choice of the particular cluster from which genotypes are to be used as parents (b) selection of a particular genotype from the selected clusters and (c) relative contribution of characters to total divergence. The results obtained in this study suggest that selected clones included in clusters $\mathrm{X}$, VIII, I and V in general can be used for hybridization programmes to create variability and exploit hybrid vigour. As the intra-cluster distances among clusters I, $\mathrm{V}$ and VIII were high, clones within a cluster are also adequately divergent for tree improvement programme through hybridization. In selecting genotypes from the already chosen groups, other important characteristics like disease resistance quality or even performance of a particular character should also be considered (CHAUDHARY et al., 1975). Therefore, male clones namely, $\mathrm{CH}$ 3004, CH 0401, CP 0207, CP 3903, CH 2604 and CP 1501 and female clones namely, $\mathrm{CH} 2703, \mathrm{CH} 2803, \mathrm{CP}$ 3703, CP 0301 and CH 3002 which also obtained higher scores as per point grading method of clonal evaluation (complete data not shown) can be selected for further breeding and hybridization programmes.

Genetic divergence studies in TCR clones grouped the 43 clones into seven clusters. The cluster strength varied from one in cluster VII to twelve in cluster VI. Cluster VII with clone TCR 040201 (female) registered the highest mean values for $\mathrm{H}, \mathrm{DBH}, \mathrm{CDM}, \mathrm{CLL}, \mathrm{FV}$ and VI. Clone TCR 120102 (female) which ranked first based on point grading (data not shown) and for most of the traits including VI, FV, DBH and CDM was included in cluster III. One male clone TCR 030101 that registered

Table 10. - Relative contribution of characters towards divergence in TCR clones.

\begin{tabular}{lcc}
\hline \multicolumn{1}{c}{ Characters } & No. of Times Ranked First & Percentage Contribution \\
\hline & & \\
Tree Height & 69 & 7.64 \\
Diameter at Breast Height & 11 & 1.22 \\
Collar Diameter & 8 & 0.89 \\
Crown Length & 100 & 11.07 \\
Cladode Length & 104 & 11.52 \\
Cladode Diameter & 80 & 8.86 \\
No. of Primary Branches & 36 & 3.99 \\
Frustum Volume & 242 & 26.80 \\
Volume Index & 253 & 28.02 \\
\hline
\end{tabular}

Table 11. - Mean and standard deviation of various characters.

\begin{tabular}{lcccc}
\hline \multicolumn{1}{c}{ Character } & \multicolumn{2}{c}{ CH/CP } & \multicolumn{2}{c}{ TCR } \\
\hline & Mcan & $\begin{array}{c}\text { Standard } \\
\text { Deviation }\end{array}$ & Mcan & $\begin{array}{c}\text { Standard } \\
\text { Deviation }\end{array}$ \\
\hline & & & & \\
Quantitative & & & & \\
& 11.76 & 1.72 & 9.66 & 2.22 \\
\hline Tree Height (m) & 5.91 & 1.23 & 5.97 & 1.82 \\
Diameter at Breast Height (cm) & 7.36 & 2.64 & 7.76 & 2.28 \\
Collar Diameter (cm) & 5.17 & 1.22 & 3.00 & 1.02 \\
Crown Length (m) & 13.66 & 2.68 & 17.50 & 3.09 \\
Cladode Length $(\mathrm{cm})$ & 0.42 & 0.09 & 0.53 & 0.08 \\
Cladode Diameter (mm) & 28.91 & 8.31 & 32.83 & 6.81 \\
No.of Primary Branches & 5425.75 & 923.48 & 5612.72 & 964.27 \\
Frustum Volume (cm $\left.{ }^{3}\right)$ & 54219.50 & 7342.99 & 42025.51 & 7929.34 \\
Volume Index (cm $\left.{ }^{3}\right)$ & & & & \\
& & & & \\
Qualitative & & & & \\
& & & & \\
\hline Axis Persistence & 3.91 & 0.52 & 7.72 & 0.88 \\
Straightness & 3.79 & 1.65 & 2.86 & 1.66 \\
Verticality & 3.36 & 1.25 & 3.44 & 1.18 \\
Bole Swelling & 1.88 & 0.49 & 1.30 & 0.96 \\
Branch Thickncss & 4.46 & 1.20 & 3.84 & 1.33 \\
Branch Angle & 2.94 & 0.79 & 1.93 & 1.10 \\
Branch Length & 2.70 & 0.73 & 2.49 & 0.88 \\
Self Pruning & 1.00 & 0.00 & 1.00 & 0.00 \\
Tolerance to Blister Bark & 4.12 & 2.43 & 2.46 & 2.36 \\
Tolerance to Root Rot & 3.00 & 0.00 & 3.00 & 0.00 \\
Tolerance to Stem Borer & 2.39 & 0.93 & 0.98 & 0.86 \\
\hline
\end{tabular}


superior values with respect to the quantitative traits too was placed in the same cluster. Cluster IV also contained clones which exhibited superior growth characteristics (TCR 110202 (male), TCR 080201 (female) and TCR 120203 (female)). Cluster V with a cluster strength of 10 contained two clones (TCR 090102 (female) and TCR 090201 (male)) which ranked among the top 10 clones as per point grading whereas, cluster VI included one promising female clone TCR 040103. The results are detailed in Tables 6 to 10.

Similar to CH/CP group, most of the clones included in clusters III, IV, V and VII recorded maximum scores for qualitative traits also. Clones in cluster IV in general could not record the maximum score for straightness (5) and branch angle (5). Ramets of these clones were found growing almost straight with one or two small bends (score 3). For branch angle, they registered a score of 1 or 3 (branch angle $>60^{\circ}$ and 45 to $60^{\circ}$ respectively). Around 77 per cent of the TCR clones were susceptible to stem borer attack. Rooting ability of all the clones was observed to be above 70 per cent.

When cluster distances were examined, it was found that cluster VII was highly divergent from all the selected clusters (III, IV, V and VI). High values for inter-cluster distances were observed between clusters IV and V, and IV and VI also. Genetic divergence was found to be moderately high when cluster distances between rest of the combinations were studied. All the selected clusters except VII (which included only one clone), registered high values for intra-cluster distances also indicating the divergence within the cluster. The results of the study recommend that male clones, TCR 110202, TCR 090201 and TCR 030101 and female clones, TCR 040204, TCR 120102, TCR 080201, TCR 120203 and TCR 090102 can be selected from the TCR group of clones for further improvement programmes.

The results on genetic divergence have got an immediate application in the establishment of clonal seed orchards. Information on genetic distance between genotypes helps in developing planting design, such that it can facilitate equal opportunity for hybridization among the genotypes and obtaining quality seed with high vigour (KUMAR, 1995).

\section{References}

Alicchio, R. and L. D. PAlenzona (1974): Phenotypic variability and divergence in disruptive selection. Theor. Appl. Genet. 45: 122-125.

BAGCHI, S. K. (2000): Divergence in Tectona grandis. Ann. For. 8: 25-37.

Balasubramanian, A. (2000): Screening for Salinity Resistance in Clones of Casuarina equisetifolia Forst. PhD. Thesis. Forest Research Institute Deemed University, Dehra Dun. India.

Chaturvedi, A. N. and L. S. Khanna (1982): Forest Mensuration. International Book Distributors, Dehra Dun, India.
Chaturvedi, O. P. and N. Pandey (2001): Genetic divergence in Bombax ceiba L. germplasms. Silvae Genetica 50: $99-102$.

Chaudhary, B. D., P. N. Bhat and V. P. Singh (1975): Genetic diversity in clusterbeans. Indian J. Agric. Sci. 45: 530-535.

Cotteril, P. P. and C. A. Dean (1990): Successful tree breeding with index selection. CSIRO Publication Service, Melbourne.

Elliott, K. J., J. M. Vose and B. D. Clinton (2002): Growth of Eastern White Pine (Pinus strobus L.) related to forest floor consumption by prescribed fire in the southern appalachians. Southern J. Applied For. 26: 18-25.

Jayaraj, R. S. C., C. S. Kannan, R. Hegde, K. G. AJit Kumar, K. S. Venkataramanan and K. Gurumurthi (1997): A comprehensive method for assessing Eucalyptus clonal trials, pp 35-42. In: IUFRO Conference on Silviculture and Improvement of Eucalyptus, Brazil (Tree Improvement strategies) Vol. 1.

KondAs, S. (1983): Casuarina equisetifolia, a multipurpose tree cash crop in India, pp. 66-76. In: Casuarina Ecology, Management and Utilization, edited by S. J. Midgley, J. W. Turnbull and R. D. Johnston, CSIRO, Canberra, Australia.

KumAR, A. (1995): Genetic Improvement of Casuarina equisetifolia. Ph.D. Thesis. Forest Research Institute Deemed University, Dehra Dun, India.

Kumar, A. and K. Gurumurthi (1998): Genetic assessment of clonal material of Casuarina equisetifolia. Indian For. 124: 237-242.

Mahalanobis, P. C. (1928): A statistical study at Chinese head measurement. J. Asiatic Soc. Bengal 25: 301-377.

Nicodemus, A. (2009): Casuarina - A Guide for Cultivation. Institute of Forest Genetics and Tree Breeding (Indian Council of Forestry Research and Education) Coimbatore, India.

Pinyopusarerk, K. and E. R. Williams (2000): Rangewide provenance variation in growth and morphological characteristics of Casuarina equisetifolia grown in Northern Australia. For. Ecol. Manage. 143: 219-232.

PRASAD, N. S. and M. J. DieTERS (1998): Genetic control of growth and form in early-age tests of Casuarina equisetifolia in Andhra Pradesh, India. For. Ecol. Manage. 110: $49-58$.

RAO, C. R. (1952): Advanced Statistical Methods in Biometric Research. John Wiley and Sons, Inc, New York.

SINGH, R. K. and B. D. CHAUdHARY (1985): Biometrical Techniques in Genetics and Breeding. International Bioscience Publications, Hissar, India.

Viswanath, S., P. ManivahaKam and M. George (2001): Casuarina equisetifolia in agroforestry practices, pp. 187-192 In: Casuarina Improvement and Utilization, edited by K. GURUMURTHI, A. NiCODEMUs and SidDAPPA, Institute of Forest Genetics and Tree Breeding, Coimbatore, India.

Warrier, K. C. S., A. Kumar and A. Balasubramanian (2004): Assessment of clones of Casuarina equisetifolia Forst. using point grading method, pp 266. In: IUFRO International Workshop on Multipurpose Trees in the Tropics: Assessment, Growth and Management, Arid Forest Research Institute (Indian Council of Forestry Research and Education), Jodhpur, India.

Herausgeber: Johann Heinrich von Thünen-Institut. Bundesforschungsinstitut für Ländliche Räume, Wald und Fischerei.

Schriftleitung: Institut für Forstgenetik, Sieker Landstraße 2, D-22927 Großhansdorf

Verlag: J. D. Sauerländer's Verlag, Finkenhofstraße 21, D-60322 Frankfurt a. M. Anzeigenverwaltung: J. D. Sauerländer's Verlag, Frankfurt am Main.

Gesamtherstellung: PPPP Norbert Wege e.K., Gladenbach — Printed in Germany. 